\title{
Farewell after 15 years
}

\author{
*Mark L Levy ${ }^{\mathrm{a}, \mathrm{b}}$ \\ a Editor-in-Chief PCRJ 1996-2010 \\ b Senior Clinical Research Fellow, Allergy \& \\ Respiratory Research Group, Centre for \\ Population Health Sciences: General \\ Practice Section, The University of \\ Edinburgh, Scotland, UK
}

*Correspondence:

Dr Mark L Levy,

Allergy \& Respiratory Research Group,

Centre for Population Health Sciences:

General Practice Section,

The University of Edinburgh,

Doorway 3, Medical School, Teviot Place,

Edinburgh, Scotland, EH8 9AG, UK

Tel: +44 (0)1461 600639

Fax: +44 (0)1461 207819

E-mail: marklevy@animalswild.com

8th November 2010
If someone had said in 1987 that in 2010 we would have representatives from the British Thoracic Society and the UK Department of Health attending the annual conference of the Primary Care Respiratory Society UK (PCRS-UK), we would not have believed them!

Over the last 20 years, the discipline of general practice (Primary Care or Family Medicine) has risen in academic stature. However, many of us who have been academics working in general practice throughout this time will be all too aware of the immense struggle that this has entailed. When we formed the UK special interest group "The GPs in Asthma Group" (subsequently the General Practice Airways Group and now the PCRS-UK) in 1987,' the management of chronic diseases like asthma and diabetes were still mainly the domain of secondary care, and community-based care was in its infancy. Primary care health professionals were relegated to dealing with the 'less serious' illnesses, and certainly were not represented at major specialist secondary care conferences nor at government level in an advisory capacity. Furthermore, at that time, there were only a handful of primary care academic respiratory publications and very few attendees from this discipline at international conferences. This has of course changed considerably, and now there is primary care respiratory representation at the highest national and international levels.

When I accepted the post as Editor-in-Chief of the Primary Care Respiratory Journal $(P C R J)$ in 1996, it was with extreme anxiety and trepidation. I was terrified at the prospect and enormity of the task of developing the then GPIAG newsletter 'Asthma News' into a fully fledged peer-reviewed academic journal - not least because of the anticipated struggle to attract high quality manuscripts which is what was needed if we were going to raise the profile of primary care respiratory research.

Looking back over the last fifteen years, for me this process has been very much like a rollercoaster. I have made many friends but have also antagonised a number of people by rejecting their publications; my lonely and responsible role as Editor-in-Chief has not been without its drawbacks! The main challenge has been to maintain academic credibility whilst satisfying the needs of the journal owners to generate enough income to survive. There certainly have been some extremely high as well as low periods and, as any editor will understand, the job presents many challenging and conflicting situations and ethical dilemmas. There were the inevitable ethical conflicts (related to editorial independence) between editors, publishers and journal owners, which can sometimes result in resignation, as was the case (fortunately only temporarily) for me - a situation which was resolved due to the incredible support from my Assistant Editors, the Respiratory Editors Group (to which I've had the honour to belong for many years), the Committee on Publication Ethics (COPE) ${ }^{2}$ and of course the Trustees of the PCRS-UK.

The highest point in my editorship was without any doubt the occasion when the PCRJ was accepted for full listing on PubMed/Medline - no mean feat as there are less than 30 primary care-related journals listed on this very important database.

I have many people to thank for enabling this and for our other achievements, particularly my Assistant Editors past and present; Chris Griffiths, John Haughney, Bob McKinley, Aziz Sheikh, Onno van Schayck and Paul Stephenson (who subsequently became the copy-editor for all $P C R J$ articles and then my invaluable Deputy Editor in 2004). In addition, development of the PCRJ has been due to the hard work of colleagues on the 
ML Levy et al.

International Editorial Board, our previous publishers Elsevier who were instrumental in guiding us through the successful PubMed application, and Lynn Danzig who has managed the journal website. I must pay tribute to the PCRS-UK chairmen, especially Dermot Ryan who developed the original idea of the journal in 1996, and lain Small the current PCRS-UK Executive Chairman who famously said that 'the $P C R J$ was not going down on his watch' and who was instrumental in ensuring the continued existence of the journal when we had to resolve major logistical problems. The ongoing support from our international colleagues of the IPCRG has been a great source of strength. I would also like to thank Tricia Bryant of Redhotirons, who was at my side in publishing the journal in the early years when we first brought the publication of the journal 'inhouse' as a GPIAG publication, and who has been with us ever since. Finally, as is often the case, I have had incredible personal support, and for this my thanks go to my beloved wife Celia who has been so supportive as my friend, confidante and adviser.

It is with great pride that we have managed to raise the profile of primary care respiratory medicine through the $P C R J$. The journal has drawn its strength and ongoing success from the rising quality of its published manuscripts which are now being frequently cited both in press and at international conferences. The journal currently stands firmly established as an academic primary care peer-reviewed journal, with a very respectable SCImago Journal Rank (SJR) of $0.182 .{ }^{3}$
The PCRJ now faces two major challenges. First, it needs to move on to the next level where it will stand as an alternative source for the first line publication of internationally-relevant respiratory research. This is at a time when universities are moving away from the current situation where journal rather than individual bibliometrics influence funding. ${ }^{4}$ At the same time, the $P C R J$ increasingly will need to satisfy the needs of so called 'grass roots' clinicians in implementing and applying research findings in practice.

As my term of office comes to an end, I look forward to the $P C R J$ 's future, safe in the knowledge that my successors, Professor Aziz Sheikh and Dr Paul Stephenson, will be able to face these challenges and take the journal to the next level. Good luck to the two of you!

\section{References}

1. Levy ML, Stephenson P, Barritt P, et al. The UK General Practice Airways Group (GPIAG): its formation, development, and influence on the management of asthma and other respiratory diseases over the last twenty years. Prim Care Resp J 2007;16(3):132-9. http://dx.doi.org/10.3132/pcrj.2007.00042

2. Committee on Publication Ethics (COPE) (http://publicationethics.org/)

3. http://www.scimagojr.com

4. Levy ML, On behalf of the editors of the Primary Care Respiratory Journal. Impact factor and its role in academic promotion. Prim Care Resp J 2009;18(3):127. http://dx.doi.org/10.4104/pcrj.2009.00051

Available online at http://www.thepcrj.org 